\section{Psychogeriatric Care}

SIR,-Your leading article on "Psychogeriatric Care" (24 July, p. 202) states that the Department of Health's emphasis on the role of geriatric medicine in the general hospital can entail removing the psychiatrist's responsibility for the care of the elderly, and in this connexion a previous paper of mine is quoted. ${ }^{1}$ In my paper, however, I emphasized that a general hospital psychiatric unit should be responsible especially for "neurotic reactions, depression, and schizophrenia of old age" and that even with other problems of the elderly there should be active cooperation between the psychiatric and geriatric departments. I need only add that at the time of writing there are 33 patients aged 65 and over in my department of 107 beds. In other words, I agree with most of the opinions expressed by Dr. T. Arie (17 July, p. 166), who, among other things, states "Old people with primarily psychiatric disorders need the environment of the psychiatric ward." His view that the vast majority of elderly people who need long-term care require a high standard of residential, as distinct from hospital, care where they would be attended by family doctors, who would call on other specialist advice as indicated, is entirely in line with my own thinking on this matter.

I would differ strongly with Dr. Arie's emphasis on the psychiatry of old age as a separate subspecialty, and the need to appoin psychiatric personnel specifically on this basis. The whole concept of defining a specialty by chronological age is at least debatable, and it is widely thought that the medical specialty of "geriatrics" was only necessitated by the neglect of this field in the past by other physicians. I would therefore make a plea for avoiding a repetition of this course of events in relationship to psychiatry. Any properly trained psychiatrist should be versed in making the relevant assessments of the various components that come into play in psychiatric ill-health in the elderly. Surely the answer lies, as Dr. Arie states, in the field of medical education, and I would have thought that it is not too late for the university departments of psychiatry and the new Royal College of Psychiatrists to play their part in this respect.-I am, etc.

\section{MaURICE Silverman}

Department of Psychological Medicine, Queen's Park Hospital,

Park

1968, 114, 493

\section{Reflux and Hernia}

SIR,-Arising from the statement in your leading article (24 July, p. 205) that intravenous metoclopramide increases the basal tone of the oesophageal sphincter, the following observation seems relevant.

We investigated a middle-aged woman with classical symptoms of oesophageal reflux by barium meal examination, giving he $10 \mathrm{mg}$ of Maxolon (metoclopramide monohydrochloride) orally beforehand to combat pylorospasm. There was no sign of reflux despite a careful search. The examination was repeated four days later without metoclopramide and this time gross reflux became apparent the moment the patient was placed in the prone or supine horizontal position.
It seems likely that the metoclopramide prevented reflux by causing the sphincter to close. Further observations on this would be of interest.-We are, etc.,

V. J. BERMAN

London W.1

D. M. KRIKLER

\section{Postgraduate Training and the} Common Market

SIR,-Your leading article (19 June, p. 665) is timely and important.

May I draw attention to one fact. Suggestions for co-ordination of education at a comparatively simple (and inexpensive level) have been in existence for some time. One is a scheme in which Professor Jean Roche of the Sorbonne and I have collaborated to arrange an exchange between our countries at a fairly advanced postgraduate level, but the problem has been that no responsible body was willing to take the first step and thus expose itself to unfavourable-if unfair -criticism.-I am, etc.

London, S.W.1

\section{C. MeDve}

\section{Pay Claims}

SIR,-I was dismayed to read in the July issue of B.M.A. News that the profession had submitted a fresh pay-claim to the new Review Body. I think there is little doubt that the last award, with a recommendation of about $30 \%$ increase, of which about $20 \%$ was finally granted, was a very great factor in stimulating the trade unions to put in ever increasing claims. At the time the Government was trying to get settlements in the region of $5 \%$, but the enormous publicity given to the "doctors' $30 \%$ rise" soon knocked that on the head, and claims of anything up to $50 \%$ became commonplace. What was the result? A transitory feeling of improvement quickly followed a proportional diminution in the value of money for everybody, severely hitting retired people and others on fixed incomes, and benefiting nobody.

I consider that the time has now come when measures similar to those taken in 1931 should be taken. On that occasion everyone from the King down to the junior office boy accepted a $5 \%$ cut, and this was followed by a general lowering of prices and a great improvement in the financial conditions. What a fine example it would be if the profession requested the Review Body to recommend a $5 \%$ reduction all round. It might well start a movement which would spread widely, and ultimately lead to a restoration of the value of the pound to the benefit of everybody.-I am, etc.,

\section{Llanbedr,}

D. MURRAy BLadon

Merionethshire

\section{Hospital Staff Appointments}

SIR,-Upon two successive short lists the applicants who were offered the posts of senior house officer gave an unqualified acceptance and the remaining candidates were dismissed and very soon obtained other posts. In each case the successful candidate then withdrew so that the post has had to be readvertised. Apart from the burden thrown upon the house officers in post be- cause of a medical vacancy, the cost of these interviews, including the expenses of the candidates and the advertisements, amounts to $£ 220$ of public money spent fruitlessly.

Irresponsible behaviour on the part of junior medical staff in this way has become increasingly prevalent over the last few years, and shows the profession up in a very bad light when it is contrasted with the sense of courtesy and responsibility exhibited by members of the professions ancillary to medicine and, indeed, of all other workers in the hospital sphere.

I question whether the medical profession is willing to allow this decadence in professional morality to continue unchecked, or whether its senior members, who themselves are frequently victims of this trend, do not feel it is time to exert some specific discipline over their own juniors. - I am, etc.,

W. E. JACOBS Deputy Group Secretary, Cromer Area Hospital Management Committee

Cromer, Norfolk

\section{Management and Medical Care}

SIR,-I was rather sad to see that in discussing the Government's proposals on reform of the N.H.S. you appear to be against its attempts to improve the management of the Service (3 July, p. 3). The statements: "What matters first in a health service is good medicine, not good management" and “... then the Health Service seems destined to have management based on cost-effectiveness. While this may be fine for industry it is not the way to provide good medical care" bear testament to your feelings.

As a hospital junior doctor for three years I would contend that the latter statement is wrong. Good medical care can only occur in the presence of, and with the aid of, good management. To me, one of the greatest frustrations in working for the N.H.S. is the evident lack of management. There are administrators who may only act according to very precise rules. No one is empowered with the responsibility to take decisions. The well-known house committees and hospital and group management committees made up of untrained, lay persons with plenty of spare time in the afternoons are surely an extraordinary way of spending millions of pounds of public money.

The poor pay and conditions of staff, in particular ancillary staff-technicians, radiographers, physiotherapists-and nurses, would not have occurred with a good management. Good medicine is very dependent upon an adequate supply of these people.

A good, and therefore powerful, management would also maintain some sort of check on the technical and professional ability of its employees and make adjustments accordingly. One is sometimes left with a feeling that patients get better despite and not because of the treatment they receive. As a member of the tax-paying public I would welcome a good and powerful management, with some control, possibly by the G.M.C., of what is after all the nation's health industry; and as a doctor and employee I would rather work under one. I would be less frustrated.-I am, etc.,

Heatherwood Hospital,
Ascot, Bucts

IAN H. PIPER 